\title{
Copyright and Trademark Offences Which Might Infringe the Consumer's Rights
}

\author{
By Imed Eddine Bekhouche
}

The objective, through this paper is to highlight the breach of consumer's rights by infringements of copyright and trademark rights, for that the armchair library approach employed. The obtained results have shown that infringements of copyright and trademark rights could breach the consumer's rights in four ways; social costs, environment, health and safety, misleading the consumer.

Keywords: Copyright; Trademark; Infringement; Consumer Rights.

\section{Introduction}

The term "counterfeiting" is commonly used to refer to a wide range of intellectual property rights violations, including trademark and copyright infringement. Technically, "counterfeiting" refers only to cases of trademark infringement, while "pirating" refers to copyright infringement. Different types of IP rights violations are overlap. For example, music piracy infringes copyright and trademark protection. Fake toys sold under a different name, but they violate the design protection of toys. According to the World Trade Organization Agreement on Trade-related Aspects of Intellectual Property Rights ("the TRIPs Agreement"), counterfeiting and piracy are defined as follows; (a) counterfeit trademark goods shall mean any goods, including packaging, bearing without authorization a trademark which is identical to the trademark validly registered in respect of such goods, or which cannot be distinguished in its essential aspects from such a trademark, and which thereby infringes the rights of the owner of the trademark in question under the law of the country of importation; (b) pirated copyright goods shall mean any goods which are copies made without the consent of the right holder or person duly authorised by the right holder in the country of production and which are made directly or indirectly from an article where the making of that copy would have constituted an infringement of a copyright or a related right under the law of the country of importation. ${ }^{1}$

\section{Background of the Study}

Today, counterfeiting industry has become a complex global business, which included the production and sale of counterfeit versions of a wide range of

*School of Law, UUM College of Law, Governance, and International Studies (COLGIS), University Utara Malaysia, 06010 Sintok, Kedah, Malaysia. Email: imed.bekhouche@ gmail.com.

${ }^{1}$ House of Commons (2007). 
products with low and high-quality levels, including electrical products, batteries, cigarettes, alcoholic beverages, golf clubs, auto parts, motorcycles and pharmaceuticals. In addition to counterfeiting branded products, intellectual property theft also includes the piracy of copyrighted products in digital and analogy formats (e.g. books, music, video and software $)^{2}$. In simple words counterfeiting means making goods that look like the original without the permission of the person or the company who invented the goods or retains the intellectual property right on the product, usually for dishonest economic or illegal purposes. How could the infringements of copyright and trademark right's breach the consumer's rights?

\section{Literature Overview}

Consumer rights and consumer protection law allow people to combat abuse of business practices. These laws are designed to keep sellers of goods and services accountable when they try to make a profit by exploiting the lack of consumer information or the ability to negotiate. Some actions considered in accordance with consumer rights laws are simply unjust, while other actions can be described as total frauds ${ }^{3}$. Consumer protection and product safety include the efforts of government, non-profit organizations, businesses and individuals to create, protect and enforce consumer rights that buy products or services. Although the idea of consumer protection is not new - since the fledging days in the US, laws on weights and uniform measures have been passed. Interest in legislation on consumer rights flourished along with progress of technological and economic aspects of society. For example, the massive commercialization of products during the industrial revolution spawned laws between the late 1890s and early 1900s regarding the purity of food. Raising awareness of product safety and consumer credit has stimulated consumer protection legislation in the 1960s and 1970s.Both common law and legality have gradually recognised the need to protect consumers from unfair commercial practices. In the nineteenth century, society developed from agrarian to industrial, and the economic philosophy of laissez faire prospered. The law of tort or negligence did not develop at this stage, since it was in its infancy. The philosophy of course at that time was that of individualism, and the basic principle was caveat emptor (let the buyer beware), so consumers had to take care of themselves. It has been considered a philosophy that the remedies should be limited to those in contract rather than in tort.

Little by little, a change in society showed us that it was not very practical; it was not enough for the consumer to take care of himself. At that time, the concept of consumerism was many, many years ago, and the concept of having a duty was not really established. There was no established legal right for a safe product or the right to safe service. The suppliers of goods controlled the market a lot and consumers of goods were very exposed to risks and dangers in the market. The courts did not really have to be the public policy developers on this. The common law has not protected the consumer and most of the cases favoured the

\footnotetext{
${ }^{2}$ Ibid.

${ }^{3}$ HG.Org.
} 
merchant. It was the law of equity that recognised the unjust situation . Consumers had little protection in the world market until the 1950s. March 15, 1962, the President of the United States John F. Kennedy, presented the Bill of Rights of Consumers to help consumers understand their rights and responsibilities. In 1985, the United Nations Assembly adopted eight basic consumer rights that led consumers to strengthen consumer protection policies around the world. March 15 declared World Consumer Rights Day ${ }^{4}$.

Original basic consumer rights are:

The right to choose

The right to safety

The right to be informed

The right to be heard

Through Consumers International, four more rights were added as follows:

The right to redress or remedy

The right to environmental health

The right to service

The right to consumer education.

The worldwide movement led to the establishment of consumer groups such as the Australian Consumer Association in 1959, and the International Organization of Consumer-Unions (IOCU), established in 1960 by the USA, Australia, the UK, Belgium and the Netherlands. It is now called Consumer International. Globalisation brings new challenges to consumer protection because many goods and services are now produced, marketed and distributed for a global market. The gap between the knowledge and power of consumers and of suppliers is even greater in global market. Recent advances in technology such as the Internet and genetically modified food today raise other challenges for consumers. Deregulation and growth in the services sector also have presented changes in the focus of consumer protection in recent years. The law is just beginning to deal with these new challenges. The most challenge nowadays for consumers is counterfeiting goods; it is very difficult to obtain accurate statistical data on counterfeiting, mainly because it is a clandestine activity. However, the US copyright industry has collected detailed information on the piracy of its products for several years. The greatest losses are in these sectors about half of all videos, over $40 \%$ of all commercial software and a third of all music records sold in 1996, were pirated copies. In Europe, counterfeit clothing is very common, both in fashion and in sportswear. A common technique is to import simple clothes and place labels in a member state of the EU, then launch products for sale in another Member State, benefiting from the free movement of goods across borders.

In the areas of spare parts, counterfeit products are part of the common problem of unauthorised spare parts. They are sold in the grey market, along with over-runs, recycled products, copies of goods and stolen pieces, which makes it

${ }^{4}$ Consumers Association of Penang. 
difficult to control the market and separate illegal and legal items ${ }^{5}$.

\section{Methodology}

Social research is a systematic study into social, political or other factconditions, to discover unknown or party known factors working behind particular phenomenon, to understand why something happens and to draw inferences and general conclusions, it is to identify the cause and effect of certain problem ${ }^{6}$. This paper is an attempt to find out the breach of consumer's rights by infringements of copyright and trademark rights. The armchair library approach employed for the collection of the primary legal materials. For this purpose, the Library of University Utara Malaysia, the Faculty of Law Library used to source the primary legal material. The secondary data, books, articles, reports and online database equally sourced through the library approach.

\section{Results}

\section{Social Costs}

Costs to combat counterfeiting and piracy. As will be indicated below, rights holders bear various costs in the fight against counterfeiting and piracy. It should be noted that since these costs are corrective, they do not go to make products better, product innovations or other improvements and therefore can be considered pure social losses.

Costs related to combating counterfeiting and piracy type of costscharacteristics.

Product protection products are modified to prevent or make them difficult to copy or fake.

Packing special packages, such as holograms and tracking and trace technologies, are used to deter counterfeiters and pirates.

Legal actions against counterfeiters and pirates.

Investigations are conducted to track counterfeiting activities.

Co-operation with governments' resources is used to provide technical and other support to governments.

Awareness initiatives are taken to raise the awareness of stakeholders of developments and issues (OECD, 2007).

Moreover, the global industry is losing a large amount to counterfeiters. These losses affect not only the producers of original items, but also the social costs. The ultimate victims of unfair competition are consumers. They receive products of poor quality at an excessive price and are sometimes in danger for health and safety. Governments lose unpaid taxes and incur significant costs to guarantee intellectual property rights. There is also growing concern that

\footnotetext{
${ }^{5} \mathrm{OECD} 1998$.
}

${ }^{6}$ Yaqin (2007). 
counterfeiting is linked to other criminal activities, such as drug trafficking, money laundering and terrorism.

It is estimated that currently counterfeit trade represents more than $5 \%$ of world trade. This high level can be attributed to a number of factors:

1) Progress in technology; 2) increase in international trade, emerging markets, and 3) Greater participation of interesting products for copying, such as clothing and brand software.

In the end, it is the consumer who pays the cost of unfair competition. Although many consumers believe that they have a bargain when they buy counterfeit products, the actual cost of the product is usually much lower. Therefore, they finally pay an excessive price for an inferior product. The low quality of many counterfeits, especially those related to health and safety, has had catastrophic consequences. It is not uncommon to find fake parts about airplanes and other vehicles that cause death and injury or counterfeiting of pharmaceuticals in hospitals. Workers are often employed in factories where fakes are made. They often work in unfavourable working conditions and are repeatedly at risk for health and safety. Moreover, they are usually poorly paid. Counterfeiting attracted both organised criminals and petty criminals, who not only received huge profits from this trade, but also used them as a means to invest in the proceeds of crime and finance other crimes ${ }^{7}$. The links between counterfeiting and other forms of criminal activity are more clearly defined. There is ample evidence that the enormous benefits of counterfeiting are used to finance other criminal acts. Obviously, we cannot measure this effect directly. However, even assuming that the fake is responsible for raising the crime rate in the United Kingdom by only $1 \%$, the economic and social cost of crime in the United Kingdom will increase by 1,700 million euros. This figure reflects the costs imposed on the criminal justice system, as well as other social costs, such as the costs of lost lives (homicides) and the costs of insurance and security for protection against crime. The additional costs of $€ 1,700$ million represent more than $80 \%$ of the total cost of the courts service in the United Kingdom and almost $5 \%$ of the total costs of the criminal justice system in the United Kingdom ${ }^{8}$.

\section{Environment}

Counterfeiting and piracy can negatively affect the environment. First, increasing the volume of seized goods causes environmental problems, since destruction can be an expensive process that generates significant waste. For example, in 2005, the European Union seized 76 million items.

Second, substandard counterfeit products can have harmful consequences for the environment. This is the chemical industry cases, which there are the use of counterfeit fertilisers causes serious damage to the environment. As an example, the destruction of crops in large areas of China, Russia, Ukraine and Italy was cited ${ }^{9}$. The environmental costs of counterfeiting for example are often

\footnotetext{
${ }^{7}$ OECD 1998.

${ }^{8}$ BASCAP (2011).

${ }^{9}$ OECD 2007.
} 
understated. Without regulation, the production of counterfeit products can present particular environmental problems. Toxic dyes and illegally chemicals disposed and uncontrolled air pollution are just some of the ways in which counterfeiting can contribute to environmental damage. The absence of known manufacturers means that legal rights or consumer rights are practically non-existent, as well as a clear understanding of who is responsible for any cleaning or impact. Likewise, eliminating fakes causes anxiety. For example, counterfeit electronic products that will be confiscated, with their unknown components, can be very difficult to dispose it in way that does not harm the environment due to the chemicals which used in the production of fake goods ${ }^{10}$. Products that violate intellectual property create important environmental problems due to the unknown nature of their components. The tendency to increase the number of such assets is of particular concern in many countries in the Asia-Pacific region that are ill-equipped to withstand far-reaching environmental consequences that require structured and evidence-based government responses. Limited supply of ozone-depleting substances (ODS), such as Hydro chlorofluorocarbons and Chlorofluorocarbons that destroy the stratospheric ozone later and are banned or restricted universally under the Montreal Protocol on Substances that Deplete the Ozone Layer unfortunately creates demand for such chemicals due to the global reduction in their use. This, in turn, creates incentives for smuggling, often using fake labels and packaging. In 2012 alone, 138 suspicious cases were identified through a mechanism supported by the United Nations Environment Program (UNEP) more than 30 percent, a total of about 1,000 tons of ODS, were considered unauthorised trade and were suspended. Trade in pharmaceutical and electronic products that infringe the intellectual property is also a problem for the countries of the AsiaPacific region. Addressing the environmental impacts of cross-border illicit trade in IP-infringing goods is a complex endeavour, far surpassing the limits of any single entity, country or region. In general companies that manufacture counterfeit products do not always take into account environmental standards that can seriously affect the local environment. If, for example, a product contains toxic substances, it is possible that this toxic substance is released into the air when the products burn. Last but not least, the destruction of seized property is an expensive process that creates a large amount of waste.

\section{Health and Safety}

The study of the "Organization for Economic Cooperation and Development" (OECD) showed that counterfeiting is not limited to luxury goods, such as watches and branded clothing, but it is extended to include pharmaceutical products, food, beverages and medical equipment, personal care, toys, tobacco and automotive items that threaten the health and safety of consumers.

Interpol states that Imitation products represent a major threat to the safety of consumers around the world: unsuspecting customers endanger their health and even their lives when they use counterfeit products, fake alcoholic beverages and travel in cars and airplanes backed by counterfeit pieces of low quality. These

\footnotetext{
${ }^{10}$ Unodc.org (2014).
} 
crimes in the field of intellectual property have virtually every product category. Today, counterfeiters produce counterfeit food and beverages, chemical products for agriculture, electrical and electronic products, auto parts, building materials and household goods, as well as luxury goods, music and unauthorised DVDs (digital versatile disk). These products are sent all over the world to emerging markets and develop in large quantities. While the World Health Organization (WHO) reveals that "counterfeit drugs and other health products can have a detrimental effect on the health of patients, including death in the most unfavourable scenarios." ${ }^{11}$ Counterfeiters and pirates have a limited interest in ensuring the quality, safety or performance of their products. This increases the potential of a negative impact on consumers. Concerns about this aspect often arise in the responses to the OECD surveys. Industries that have health and safety consequences include automotive, electrical components, food and beverages, chemicals, toiletries and household products, pharmaceuticals and tobacco products.

- In the automotive sector, the inferior replacement parts falsely carrying the brand name of trusted manufacturers. Counterfeits include brake pads, hydraulic hoses, engine and chassis parts, suspension and steering components, and airbag mechanisms. In some cases, the deficiencies found in these products seriously compromise the safety of the vehicle.

- In the field of electrical components, fake circuit breakers have been found that it was incorrectly calibrated or that it would be manufactured using poor quality materials. These shortcomings caused fires and fatal electric shock.

- -In the food and beverage sector, few will consciously buy fake food or drink, in part due to possible health risks. These risks range from general malaise, serious illnesses and even death. As discussed in the sectoral assessment, this was the case of a weakly distilled crude alcohol and fake baby formula.

- In the case of pharmaceutical products, products that violate the sign may include the correct ingredients in the wrong quantities or may be formulated in accordance with the wrong formula. Products may also contain inactive or even toxic ingredients. Ailments which could be remedied by genuine products may go untreated or worsen; in some cases, this may lead to death. Most purchasers of counterfeit pharmaceuticals are likely to be completely unaware that they become victims ${ }^{12}$.

- In the personal care products and cosmetics, China is one of the largest personal health care markets in the world in terms of per capita expenditure; it is also a hot spot for counterfeit cosmetics. Leading personal care giant Procter \& Gamble, estimates that counterfeit products in China cost more than $10 \%$ in the form of lost profits. In this line, the China Consumers Association (CCA) states that contraband and fake cosmetics constitute the majority of consumer complaints, highlighting the fact that grey market cosmetics are also unsafe after passing strict

\footnotetext{
${ }^{11}$ LLC, Helix (2014).

${ }^{12}$ (OECD, 2007).
} 
testing procedures legitimate personal care items. Personal hygiene items, such as shampoos, toothpaste, lotions, face creams and makeup, are often subject to counterfeiting.

- In the cigarettes, Cigarette counterfeiting trading is a rapidly growing global problem. Nearly $90 \%$ of cigarettes smuggled under the Philip Morris International brands, captured by governments in 2002, were in fact counterfeit. Tobacco producers not only lose hundreds of millions of dollars each year, but smokers who cheated to buy fake cigarettes are at greater risk than they already face. For example, in a recent BBC documentary, it has been reported that counterfeit cigarettes are "75\% more". Resin, 28\% more nicotine and 63\% more carbon monoxide "than real cigarettes in the UK market, and many even" contaminated with sand and other packaging materials, such as plastic pieces. "It is estimated that one out of every five of all cigarettes sold in the United Kingdom were counterfeit" $" 13$.

Counterfeit products are not regulated and are unsafe. Every year, thousands of consumers who live and work in the G20 countries are victims of accidents and injuries due to unregulated counterfeit products. Many, if not most, of these products are bought unwittingly by consumers. Unfortunately, 3000 consumers lose their lives every year because of their exposure to dangerous counterfeit products (mainly through counterfeit food products and medicines). Based on conservative assumptions, the economic value of lives lost as a result of a counterfeit can reach 14.5 billion Euros per year in all G20 countries. Injuries and diseases associated with counterfeiting also exert pressure on medical services within the G20. Although there are few good sources of information on the overall prevalence of accidents and diseases caused by counterfeiting, even the most modest assumptions indicate that during the G20, the cost of medical services will probably exceed $€ 100$ million. ${ }^{14}$

\section{Misleading the Consumer}

According to the $\mathrm{OECD}$, counterfeit products include all products designed to accurately mimic the appearance of another person's product in order to deceive consumers. They may include the unauthorised production and distribution of products protected by intellectual property rights, such as copyrights, trademarks and commercial names. In many cases, several types of violations can often be duplicated: music piracy significantly violates copyrights and even trademarks; fake toys violate design protection. Therefore, the term "counterfeiting" refers to piracy and related issues, such as a copy of the package, labelling or any other important feature of the products. Consumers often do not know if the products they buy are counterfeit. One reason is that the art of copying, packaging and labelling has become more sophisticated, which makes it difficult to distinguish between counterfeit and original products. And far from selling in the corners

\footnotetext{
${ }^{13}$ Reichelt (2007).

${ }^{14}$ BASCAP (2011).
} 
of shady streets, counterfeit goods began to flow in conventional distribution systems, as well as on supermarket shelves along with genuine products ${ }^{15}$.

Fake products are two types - counterfeit products and pass-off products. Counterfeit products are fake products that have the same name/package/ graphics/ colour combination. And also, the same name and address of the original manufacturer. These are products that look exactly like a real product. It is increasingly difficult to distinguish the true "ponds" of talc powder and the "plus clinical" shampoo from counterfeit products. However, Pass-off products use similar sounding or are similar in spelling (for example 'luk' for 'lux', '510' for '501', 'saveena' for 'sabeena'), they use similar type of packaging, colours or designs. They are brought out with motive of misleading and cheating ordinary consumers who are uneducated or in a hurry when purchasing products. ${ }^{16}$

The following case may serve as good example ${ }^{17}$ :

\section{The Facts}

The plaintiff, a Thai public limited company, the registered proprietor of canned food under the "Smiling Fish" brand and device, a trade mark registered in Malaysia. Its logo depicted a caricature of a fish below the words "Smiling Fish". The plaintiff contended that the defendant had been manufacturing and distributing canned sardines, like theirs, with a similar get up in packaging, with the words "Smiling Brand" as opposed to "Smiling Fish" appeared in addition to pictures of a blue coloured sardine and chillies. The plaintiff alleged that the depiction of these marks on the defendant's canned sardines was an infringement of their copyright, causing irreparable damage to their business goodwill, reputation and causing them to suffer loss and damage. The plaintiff asserted that they have been issued with ISO certification and awarded "Super Brand" status in Thailand and have been selling their canned sardines extensively in Malaysia, including Sarawak. Upon discovery of the alleged infringement by the defendant, the plaintiff had through their agent purchased the defendant's canned sardines at five supermarket outlets in Kuching, Sibu, and Miri respectively. They said the similarity of the setup of the defendant's canned sardines with theirs has been capable of misleading and/or deceiving the public that the defendant's canned sardines were manufactured or imported, distributed and sold by them with the plaintiff's authority or consent.

\section{The Court's Decision}

There is extreme similarity in the two get ups such that a person who sees one in the absence of the other "would be liable to be deceived and to think that the trade mark before him is the same as the other, of which he has a general recollection" "18. This is especially so when the plaintiff's canned sardines are

\footnotetext{
${ }^{15}$ Haie-Fayle \& Hübner (2007).

${ }^{16}$ Krishnamacharyulu \& Ramakrishnan (2011).

${ }^{17}$ Kuang Pei San Food Products public company limited, Thailand v. Wees Marketing Co., Malaysia.

${ }^{18}$ Per Sargant, J. in Sandown Ltd's Application (1914) at 205.
} 
placed on the supermarket shelves with the real picture of the blue fish facing outwards (not that of the caricature of the "Smiling Fish"). When in this position, the defendant's canned sardines would be deceptively similar to theirs because of the same picture of the blue fish with the chillies, tomatoes and green salad in the defendant's get up.

I agree therefore that these two get ups would cause confusion in the mind of the ordinary general public though not one who would spend hours scrutinizing the details of canned products on the shelves of supermarkets and this I hold, despite the defendant's contention that the words "Smiling Fish" used by the plaintiff in their get up and "Smiling Brand" used in the defendant's get up are phonetically different when pronounced in Mandarin.

I accept too the evidence of both parties that the plaintiff's canned products bearing the said get up had been in the market in Sarawak for more than twenty years and in that time, has penetrated the market and the minds of the general public so as to enjoy the sales which had benefitted the plaintiff and its former distributor, Wee Ping Trading Sdn Bhd. The confusion which I believe has arisen in this case over the two get ups would probably cause irreparable damage to the plaintiff's business and goodwill as they alleged.

For these reasons, I allow the plaintiff's application with costs of RM 8,000.00.

\section{Conclusion and Recommendations}

Today, there is a great need to increase awareness and educating the public concerning counterfeit products. No anti-counterfeiting campaign would be complete without public awareness and education.

A trademark owner may:

(1)Educate the public on the dangers and negative effects of counterfeiting and on how to reduce the risk of purchasing counterfeit products. Helpful messages could include:

(a) What is a counterfeit product and why the public should be vigilant,

(b)The dangers of buying cheap products over the Internet or from other unknown entities,

(c) Good purchasing practices and cultivating them, and

(d)Identifying lawful sources of purchasing genuine products.

(2)Educate consumers on how to identify counterfeit products (including how to recognise anti-counterfeiting technologies on packages, labelling, and the products themselves) and instructions on what to do when they have identified a counterfeit product;

(3)Provide individual strategy for educating and increasing awareness tailored to different categories of consumers. These creative strategies could take the form of public service announcements, educational fliers and communication tools that can reach wide distribution, toll-free numbers 
on labels or packaging; posting messages on appropriate industry and private group websites.

Counterfeiters thrive on the ignorance of consumers. Well-informed and educated consumers will help conquer back a portion of the market for original goods.

Consumer education and public awareness campaigns on consumer issues specially fight against counterfeit; the role of government is educating the public about counterfeit goods and illustrates the dangerous effect of this product on them. The consumer education tools include utilization of avenues such as trade exhibitions for creating awareness and dissemination of public education on counterfeit goods including counterfeit medicine and other issues of significance to consumers.

At the end consumers have a duty to avoid purchasing fake products. Here are some suggestions to avoid purchasing the fake goods;

- Scrutinise labels, packaging and contents; look at the words and designs.

- Seek only "authorised dealers" when purchasing replacement parts.

- Watch for deals that allow you to purchase without VAT or Sales Tax.

- Avoid purchasing from websites that are not secure or that do not allow you to phone your payment details.

- If you see a deal that is "too good to be true" - it probably is fake.

- Pay attention to performance problems.

Counterfeiting produces many victims. From traders, to authorities, to consumers; all face the same enemy, but are struggling with their own struggles. Traders/brands will mainly deal with counterfeiting, as it is a violation their intellectual property rights. Consumers could lose confidence in the brand if they use a counterfeit product without knowing it. Authorities are fighting against counterfeiting, as this affects the economy growth of the country, as well as the health and safety of citizens. Authority protects business and citizens and collaborates with foreign authorities to get better results. Consumers are also victims: they are deceived by the seller who sends useless and sometimes dangerous product. If the consumer receives such counterfeit product, it can be exposed to all kinds of risks (health, quality, and so on). Customs authorities can stop and destroy the package so that he loses the product for which he has paid. Consumers can be discouraged from buying online. In reality, all these parts are victims of counterfeit products, cooperation is necessary to combat counterfeiting.

\section{References}

BASCAP (2011). 'Estimating the global economic and social impacts of counterfeiting and piracy - a report commissioned by business action to stop counterfeiting and piracy, in Frontier Economics, February 2011

Consumers Association of Penang, at https://www.consumer.org.my/index.php/comp laints/rights/256-your-basic-rights-as-a-consumer. 
Haie-Fayle, L. \& W. Hübner (2007). 'Counterfeiting and piracy - Fakes, facts and figures', in, OECD Observer No. 262, July 2007. http://www.oecdobserver.org/news/archi vestory.php/aid/2278/Counterfeiting_and_piracy_html

HG.Org. https://www.hg.org/consume.html

House of Commons, Ottawa, Canada (2007). Counterfeiting and Piracy are theft, Report of the Standing Committee on Industry, Science and Technology, June 2007, 39th Parliament, 1st Session. http://www.parl.gc.ca/HousePublications/Publication.as px ?DocId=3060548\&Language $=E \&$ Mode $=1 \&$ Parl=39\&Ses $=1 \&$ File $=21 \quad \mathrm{https}: / /$ www.consumer.org.my/index.php/complaints/rights/256-your-basic-rights-as-aconsumer

Krishnamacharyulu, C.S.G. \& L. Ramakrishnan (2011). Rural marketing text and cases. Dorling Kindersley (India) Pvt. Ltd.

LLC, Helix. (2014). 'IP Enforcement Guidelines - IP Enforcement - Intellectual Property Agency'. Aipa.Am. http://www.aipa.am/en/ip-infringement/

OECD 1998. The Economic Impact of Counterfeiting. Paris, France.

OECD 2007. The economic impact of counterfeiting and piracy: Executive Summary.

Reichelt, K.M. (2007). Avoiding Counterfeit Goods: A How-To Guide for Consumers. International Intellectual Property Institute

Unodc.org. (2014). 'Counterfeit: Don't Buy Into Organized Crime'. http://www.unodc. org/counterfeit

Yaqin, A. (2007). Legal research and writing: Kelana Jaya, Selangor: Malayan Law Journal.

\section{Cases}

Kuang Pei San Food Products public company limited no. 88/9 moo 4, kuang pei san road tumbon nathamneua, amphur muang trang 92190, Thailand v. Wees Marketing Co. Sdn. bhd. no. 135, lot 854, demak laut industrial park phase 3, jalan bako 93050 Kuching, Sarawak, Malaysia. Malaysia, the High Court in Sabah and Sarawak at Kuching. Suit No. 22-231-2009-III. Sgd. (Y.A. PUAN RHODZARIAH BUJANG) Judicial Commissioner High Court II Kuching in 20 May 2010. https://www.cljlaw.com/Mem bers/DisplayCase. aspx $?$ CaseId $=2881498625 \&$ SearchId $=9$ psb

Sandown Ltd's Application (1914) 31 RPC 196 